\title{
Efficient malic acid production from glycerol with Ustilago trichophora TZ1
}

Thiemo Zambanini ${ }^{1}$, Eda Sarikaya' ${ }^{1}$, Wiebke Kleineberg ${ }^{1}$, Joerg M. Buescher ${ }^{2}$, Guido Meurer ${ }^{2}$, Nick Wierckx* and Lars M. Blank'

\begin{abstract}
Background: The large surplus of crude glycerol, as main low-value waste stream in biodiesel production, has led to the investigation of new possibilities for the production of value-added chemicals from this feedstock. New and efficient (bio-) catalysts are needed that are able to convert glycerol to versatile chemical building blocks. This would contribute to further develop away from a mainly petroleum based, to a sustainable, bio-based industry. One promising group of discussed building block chemicals are dicarbonic acids.

Results: Here, we report the efficient synthesis of malate from glycerol using Ustilago trichophora RK089, which was identified in a screening of 74 Ustilaginaceae. For economically feasible production that can compete with existing processes, a high productivity is required. By adaptive laboratory evolution, the growth and production rate were increased by 2.5- and 6.6-fold, respectively. Further medium optimization increased the final titer, yield, and overall production rate to $196 \mathrm{~g} \mathrm{~L}^{-1}, 0.82 \mathrm{gmal}_{\mathrm{maly}} \mathrm{g}_{\mathrm{g}}^{-1}$ and $0.39 \mathrm{~g} \mathrm{~L}^{-1} \mathrm{~h}^{-1}$, respectively.

Conclusions: This titer is the highest reported for microbial malate production, making U. trichophora TZ1 a promising microbial production host for malate from crude glycerol, especially since it is not genetically engineered. Since this production process starts from an industrial waste stream as substrate and yields an interesting platform chemical, which can be used to replace petro-chemicals, it greatly contributes to a sustainable bio-economy.
\end{abstract}

Keywords: Adaptive laboratory evolution, Glycerol, Malate, Medium optimization, Ustilago trichophora

\section{Background}

In recent years, it has become apparent that a switch from our mainly petrochemical-based industry toward a bio-based, carbon neutral economy is inevitable. This switch requires new precursors for many different chemicals in a broad range of sectors, such as the mobility, polymer, food additives, and pharmaceutical industries, which still rely mainly on fossil resources.

One chemical of interest is the $\mathrm{C} 4$ dicarbonic acid malic acid, which has been used as acidulant in foods and beverages for decades [1]. Malate has great potential as building-block chemical, for instance as a biobased precursor for maleic anhydride, or for substituted

\footnotetext{
*Correspondence: nick.wierckx@rwth-aachen.de

${ }^{1}$ Institute of Applied Microbiology-iAMB, Aachen Biology

and Biotechnology-ABBt, RWTH Aachen University, Worringerweg 1 ,

52074 Aachen, Germany

Full list of author information is available at the end of the article
}

tetrahydrofuran derivatives [2, 3]. It can also be used for the production of bio-degradable polymers [4]. In 2004, Werpy and Petersen considered 1,4-diacids (malate, succinate, fumarate) one of the twelve most promising chemicals to produce from biomass [3]. Since it is, as intermediate of the tricarboxylic acid cycle, a natural product of many microbes, microbial production is considered to be promising [4].

Indeed, the possibility of microbial production of malate has already been known and investigated for a long time. In 1962, Abe et al. [5] selected Aspergillus flavus as production strain and patented the production process reaching a final titer of $58 \mathrm{~g} \mathrm{~L}^{-1}$ at a rate of $0.27 \mathrm{~g} \mathrm{~L}^{-1} \mathrm{~h}^{-1}$ and with a yield of $0.78 \mathrm{~mol}$ malate per mol glucose. However, A. flavus is known to produce aflatoxins excluding it as industrially applicable production strain, especially for food-grade malate [6]. To circumvent such problems, well-established model organisms, 
such as Saccharomyces cerevisiae, Aspergillus niger, and Escherichia coli, were engineered for microbial malate production [7-10]. These efforts resulted in production values comparable to the ones with A. flavus. In 2013, Brown et al. [11] reported a production process for malate with Aspergillus oryzae producing $154 \mathrm{~g} \mathrm{~L}^{-1}$ malate with a rate of $0.94 \mathrm{~g} \mathrm{~L}^{-1} \mathrm{~h}^{-1}$ and a yield of $1.38 \mathrm{~mol} \mathrm{~mol}^{-1}$ on glucose. A. oryzae is a close relative to A. flavus which produces no aflatoxins and is generally regarded as Safe (GRAS).

However, production processes with Aspergillus species have certain drawbacks, such as the filamentous growth, which results in difficulties with the oxygen supply during large-scale fermentation [12]. Therefore, a new, unicellular production strain would be favorable. In 2014, Geiser et al. [13] screened 68 Ustilaginaceae for the production of organic acids. They found many strains from this family to produce malate naturally, besides other organic acids, such as succinate or itaconate. Ustilaginaceae are a family of plant pathogenic fungi, of which the haploid form grows unicellularly. Further, they show tolerance to high concentrations of organic acids and they do not produce toxins, which makes them industrially applicable, even for the food industry.

Thus far, most malate production studies have focused on glucose as a substrate. Recently, glycerol has been heralded as new substrate for the production of chemicals [14]. The rising production of biodiesel, 123 million tons per year predicted by 2016 [15], is accompanied by the production of around 19 million tons per year of crude glycerol as main waste stream $(10 \%(w / v))$. Although this glycerol itself has been considered one of the most important building blocks to be produced from biomass [16], the large volume of crude glycerol side streams has become a burden rather than a blessing. The overall process of biodiesel production would become economically more favorable, if new applications for the resulting crude glycerol were found. One application discussed frequently over the last years is the microbial conversion of the crude glycerol to value-added chemicals [14, 17]. Different production processes using glycerol as precursor have been reported, such as the production of 1,3-propanediol [18, 19], polyhydroxyalkanoates [20], lipids [21], succinate [22], citrate [23], and erythritol [24]. The possibility of malate production from glycerol, however, has thus far only been proposed, but not investigated [17]. One advantage of the microbial conversion of glycerol to C4 dicarboxylic acids, such as malate or succinate is the possibility of $\mathrm{CO}_{2}$ fixation through the action of pyruvate carboxylase. By this reaction, the three-carbon pyruvate and $\mathrm{CO}_{2}$ are converted to the four-carbon oxaloacetate, theoretically enabling a process with a net carbon fixation [17].

In this study, we present the yeast-like growing smut fungus Ustilago trichophora TZ1 as new production host for malate from glycerol, combining high productivity with little by-product formation and avoidance of consumer opinion and regulatory restrictions, due to production with a genetically not modified organism.

\section{Results and discussion}

Selection and evolution of Ustilago trichophora as best producer of malate from glycerol

Ustilaginaceae are known to produce a broad variety of secondary metabolites and other products from glucose naturally, such as itaconate, malate, and succinate [13]. In order to identify strains that produce acids from glycerol efficiently, 74 Ustilaginaceae were initially screened on solid glycerol medium with methyl red as $\mathrm{pH}$ indicator. The seven best strains were chosen for further characterization based on growth rate (colony size) and acid production (pink halo) (Fig. 1a). Subsequently, these seven strains were assessed in more detail in liquid cultures in 2-(N-morpholino)ethanesulfonic acid (MES)buffered modified Tabuchi medium (MTM) containing $50 \mathrm{~g} \mathrm{~L}^{-1}$ glycerol and $0.8 \mathrm{~g} \mathrm{~L}^{-1} \mathrm{NH}_{4} \mathrm{Cl}$. U. trichophora (CBS 131473) was selected as the best growing strain with a growth rate of $0.11 \pm 0.00 \mathrm{~h}^{-1}$, producing $2.3 \pm 0.1 \mathrm{~g} \mathrm{~L}^{-1}$ malate in $216 \mathrm{~h}$ at an overall rate of $0.01 \pm 0.00 \mathrm{~g} \mathrm{~L}^{-1} \mathrm{~h}^{-1}$ (Fig. 1e). Although U. trichophora was the best growing and producing strain on glycerol out of the 74 screened strains, these values are low compared to growth and malate production of this strain on glucose under the same conditions $\left(0.45 \pm 0.02 \mathrm{~h}^{-1}\right.$ and $0.08 \pm 0.00 \mathrm{~g} \mathrm{~L}^{-1} \mathrm{~h}^{-1}$, respectively), indicating that its metabolic capacity has room for improvement on glycerol.

Adaptive laboratory evolution (ALE) is a method frequently used to improve different characteristics of microbes by adapting them to environmental conditions, such as sub-optimal $\mathrm{pH}$-values or temperatures, different stress factors or the ability to utilize non-preferred carbon sources $[25,26]$. Especially, the potential to improve the growth rate on non-preferred carbon sources has been shown in many studies. For instance, Sonderegger et al. [27] and Kuyper et al. [28] could improve the growth rate of engineered S. cerevisiae strains on xylose and Ibarra et al. [29] were able to double the growth rate of E. coli on glycerol at $30{ }^{\circ} \mathrm{C}$ by ALE. Using a simple re-inoculation scheme with two parallel shake flask cultures, as described in "Methods" section, the growth rate of $U$. trichophora was improved after 58 days with 

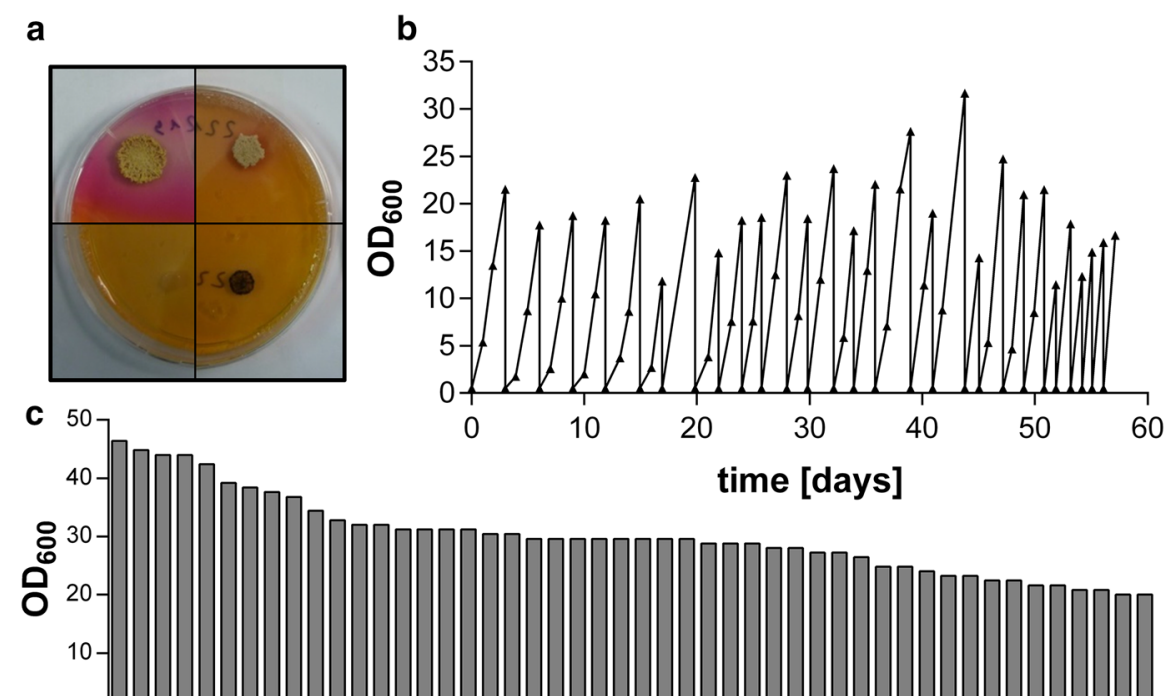

0

- NoO F-
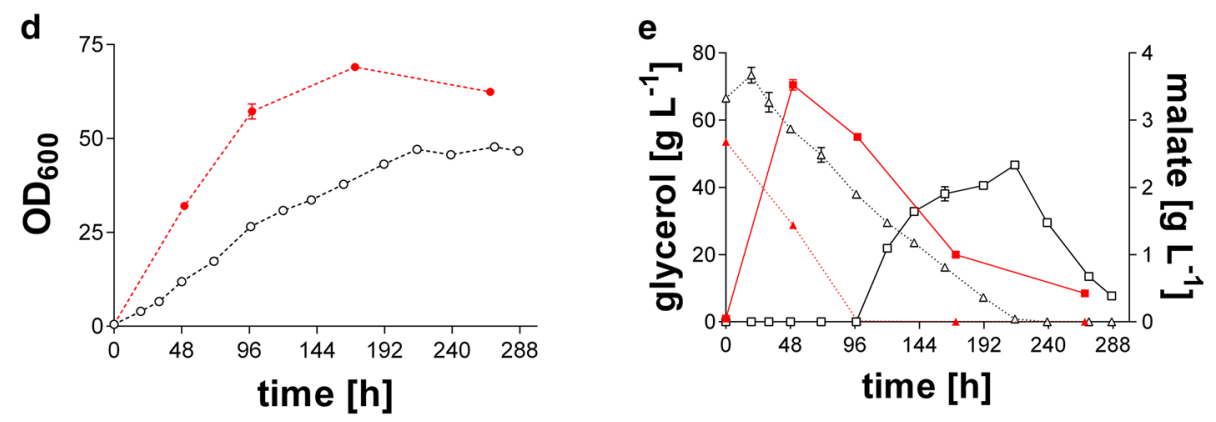

Fig. 1 Screening and ALE for the production of organic acids from glycerol. a Four Ustilaginaceae in solid medium screening with glycerol as sole carbon source and methyl red as $\mathrm{pH}$ indicator, pink halos indicate acid production, b ALE of U. trichophora on glycerol as sole carbon source. A single representative culture is shown, c Rank ordered $\mathrm{OD}_{600}$ after $24 \mathrm{~h}$ of 48 single colonies from the two parallel $U$. trichophora TZ1 cultures, the first numbers on the X-axis indicate from which parallel line the clone is derived, $\mathbf{d}$ Comparison of growth for U. trichophora TZ1 (closed symbols, red) and wild type (open symbols, black) on glycerol, e Comparison of acid production (squares, solid lines) and glycerol consumption (triangles, dotted lines) for U. trichophora TZ1 (closed symbols, red) and wild type (open symbols, black)

27 re-inoculations, corresponding to approximately 140 generations (Fig. 1b). Screening 48 single colonies of the evolved cultures (Fig. 1c) resulted in a clonal culture with increased growth rate of $0.26 \pm 0.03 \mathrm{~h}^{-1}$ for the best colony, Ustilago trichophora TZ1, which constitutes a 2.4-fold improvement over the wild type. It should be noted that, as known for Ustilaginaceae [13], the $\mathrm{OD}_{600}$ of $U$. trichophora generally continues to increase after nitrogen limitation (Fig. 1d), likely as a result of intracellular lipid accumulation and associated morphological changes [30]. The indicated growth rates were therefore assessed separately in cultures with a higher sample resolution in the initial growth phase (data not shown). The malate production reached $3.5 \pm 0.1 \mathrm{~g} \mathrm{~L}^{-1}$ within $50 \mathrm{~h}$, corresponding to a malate production rate of $0.07 \pm 0.00 \mathrm{~g} \mathrm{~L}^{-1} \mathrm{~h}^{-1}$ (Fig. 1e).
Medium optimization increases malate production with $U$. trichophora TZ1

To further improve the malate production of $U$. trichophora TZ1, the influence of different medium components (MES and $\mathrm{CaCO}_{3}$ buffer; 10, 50, $100 \mathrm{mg} \mathrm{L}^{-1}$ $\mathrm{FeSO}_{4} ; 0.125,0.25,0.5,1 \mathrm{~g} \mathrm{~L}^{-1} \mathrm{KH}_{2} \mathrm{PO}_{4}$ ) was investigated in 24-deep well plates. Different $\mathrm{FeSO}_{4}$ concentrations were tested, since $\mathrm{FeSO}_{4}$ is known to influence organic acid production in $A$. terreus [31]. Influences of MES and $\mathrm{CaCO}_{3}$ buffer on organic acid formation in Ustilaginaceae were already shown by Geiser et al. [13] and the impact of $\mathrm{KH}_{2} \mathrm{PO}_{4}$ concentration on organic acid production has been shown by Jeon et al. [32]. Changing the $\mathrm{FeSO}_{4}$ and $\mathrm{KH}_{2} \mathrm{PO}_{4}$ concentrations did not influence growth or malate production for $U$. trichophora $\mathrm{TZ1}$ (data not shown). A change from MES buffer to $\mathrm{CaCO}_{3}$ 
buffer $\left(33 \mathrm{~g} \mathrm{~L}^{-1}\right)$, however, resulted in a higher titer of $5.3 \pm 0.3 \mathrm{~g} \mathrm{~L}^{-1}$ malate after $98 \mathrm{~h}$ of cultivation upon glycerol depletion. In MES-buffered cultures, $\mathrm{pH}$-values decreased during cultivation, while $\mathrm{pH}$-values in cultures with $\mathrm{CaCO}_{3}$ stayed constant. Given the higher buffer capacity of $\mathrm{CaCO}_{3}$, it is likely that in MES-buffered cultures $\mathrm{pH}$ decreases to below the minimum for malate production of $U$. trichophora TZ1. A similar phenomenon was also observed for certain itaconate producing Ustilago strains [13]. Another advantage of $\mathrm{CaCO}_{3}$ as buffer could be the additional supply of $\mathrm{CO}_{2}$, since the microbial production of malate via pyruvate likely relies on $\mathrm{CO}_{2}$ as co-substrate. Upon reaction of malic acid with $\mathrm{CaCO}_{3}, \mathrm{HCO}_{3}{ }^{-}$is formed, which is in equilibrium with dissolved $\mathrm{CO}_{2}$ dependent on the $\mathrm{pH}$. This can provide an additional $\mathrm{HCO}_{3}{ }^{-}$supply for pyruvate carboxylase to form oxaloacetate from pyruvate. Indeed, feeding of additional $\mathrm{CO}_{2}$ to an engineered malate producing S. cerevisiae strain significantly improved malate production [33]. By this, the malate production can theoretically be enhanced to yield $1 \mathrm{~mol}$ malate per mole of glycerol [7].

Since the malate production rate did not decrease until glycerol depletion, the initial glycerol concentration was increased to $200 \mathrm{~g} \mathrm{~L}^{-1}$. In these cultures, the malate concentration reached $129 \pm 5 \mathrm{~g} \mathrm{~L}^{-1}$ upon glycerol depletion (Fig. 2). This concentration was only observed upon dissolution of solid medium components with $\mathrm{HCl}$ prior to filtering for $\mathrm{HPLC}$ analysis. If $\mathrm{HCl}$ addition was omitted, the concentration reached $28 \pm 2 \mathrm{~g} \mathrm{~L}^{-1}$ after $96 \mathrm{~h}$ of cultivation, after which it dropped to $14 \pm 1 \mathrm{~g} \mathrm{~L}^{-1}$ and stayed constant throughout cultivation. These results clearly show that the produced malate in combination with $\mathrm{CaCO}_{3}$ forms $\mathrm{Ca}$-malate, which precipitates after

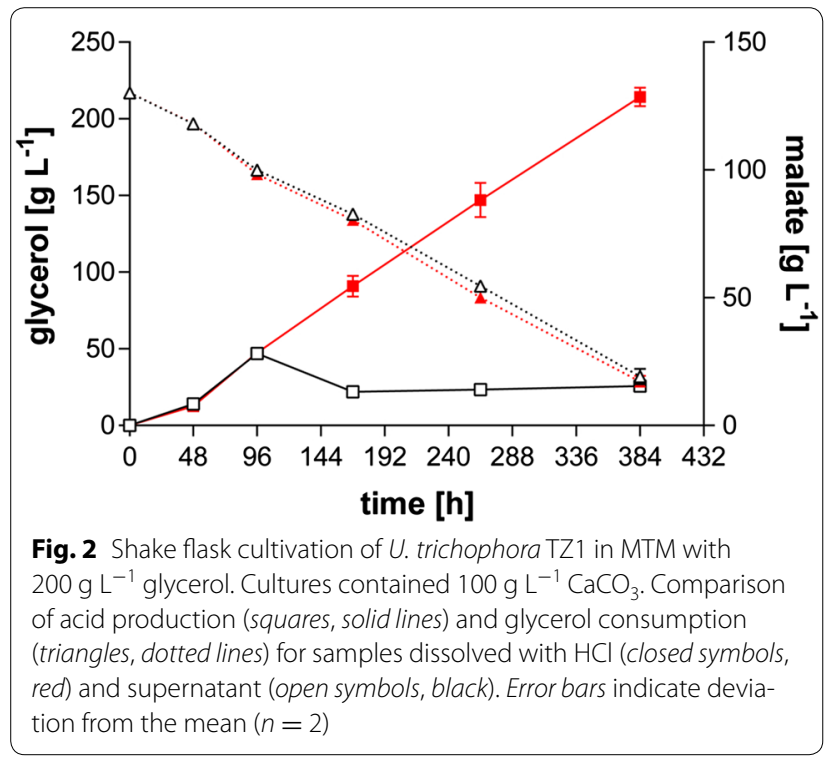

a brief super-saturation to its solubility limit. This solubility is somewhat higher than reported values (approximately $10 \mathrm{~g} \mathrm{~L}^{-1}$ ) [34], which is likely due to differences in temperature and the presence of cells and other buffering agents.

\section{Higher initial glycerol concentration further increases malate production}

To further investigate the influence of starting glycerol concentrations on malate formation, the initial glycerol concentration was varied between 150 and $400 \mathrm{~g} \mathrm{~L}^{-1}$ in $50 \mathrm{~g} \mathrm{~L}^{-1}$ increments (Fig. 3). Growth decreased with increasing initial glycerol concentrations (Fig. 3a),

a
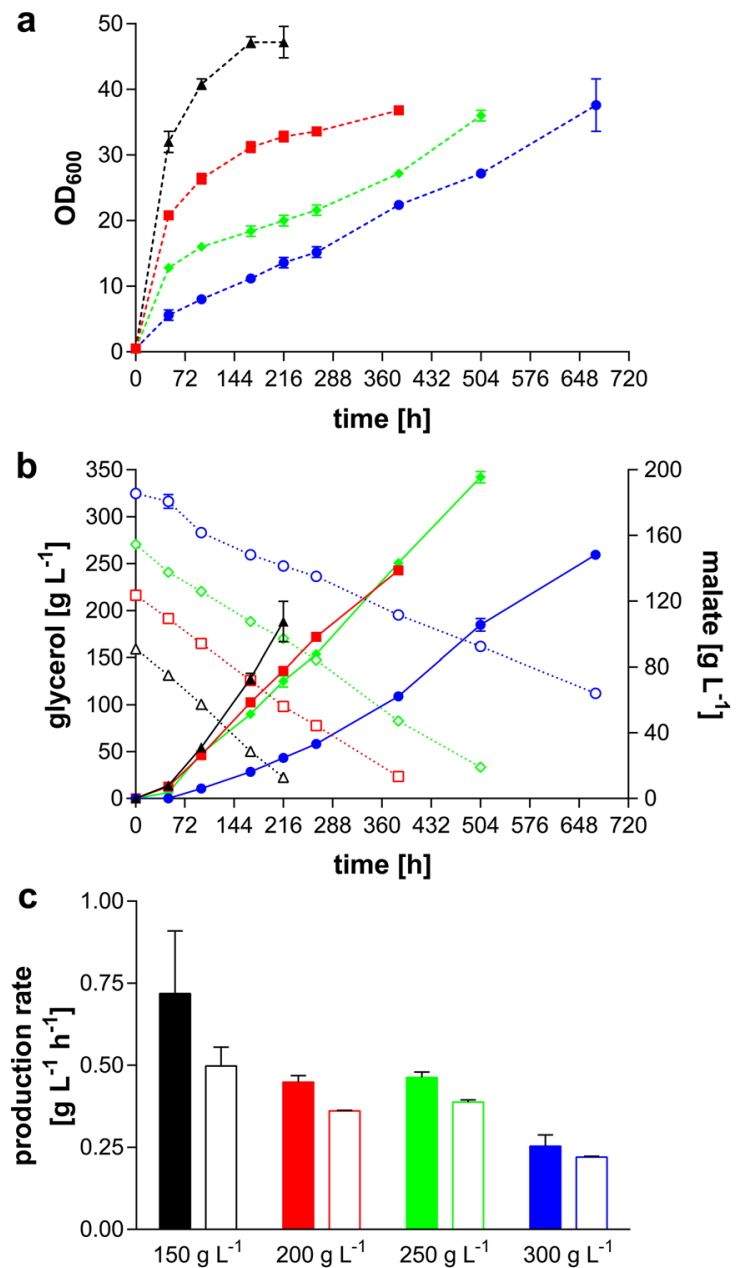

Fig. 3 Shake flask cultivation of U. trichophora TZ1 in MTM with differing glycerol concentrations. Cultures contained $100 \mathrm{~g} \mathrm{~L}^{-1} \mathrm{CaCO}_{3}$. a Comparison of growth. b Comparison of acid production (solid lines, closed symbols) and glycerol consumption (dotted lines, open symbols). $150 \mathrm{~g} \mathrm{~L}^{-1}$ (triangles, black), $200 \mathrm{~g} \mathrm{~L}^{-1}$ (squares, red), $250 \mathrm{~g} \mathrm{~L}^{-1}$ (diamonds, green), $300 \mathrm{~g} \mathrm{~L}^{-1}$ (circles, blue). c Maximal (filled bars) and overall (open bars) production rate per glycerol concentration. Error bars indicate deviation from the mean $(n=2)$ 
leading to complete growth inhibition at concentrations exceeding $300 \mathrm{~g} \mathrm{~L}^{-1}$ (data not shown). An initial glycerol concentration of $150 \mathrm{~g} \mathrm{~L}^{-1}$ led to the highest overall volumetric production rate of $0.50 \pm 0.08 \mathrm{~g} \mathrm{~L}^{-1} \mathrm{~h}^{-1}$. Furthermore, malate production rates and glycerol uptake rates remained constant until depletion (Fig. 3b). Due to handling issues (i.e., shaking of viscous liquid), samples for $300 \mathrm{~g} \mathrm{~L}^{-1}$ could not be taken after $672 \mathrm{~h}$. Hence, the maximal malic acid titer of $196 \pm 5 \mathrm{~g} \mathrm{~L}^{-1}$ was reached with $250 \mathrm{~g} \mathrm{~L}^{-1}$ glycerol as starting concentration after $504 \mathrm{~h}$, corresponding to an overall production rate of $0.39 \pm 0.01 \mathrm{~g} \mathrm{~L}^{-1} \mathrm{~h}^{-1}$ (Fig. 3b). This culture also had the highest yield of $0.82 \pm 0.02 \mathrm{~g}_{\text {mal }} \mathrm{g}_{\text {gly }}^{-1}(=0.57 \pm 0.01 \mathrm{~mol}-$ mal $\mathrm{mol}_{\text {gly }}^{-1}$ ) although in general the cultures did not show large differences in yield and no clear trend could be observed (average for all cultures: $0.74 \pm 0.9 \mathrm{~g}_{\mathrm{mal}} \mathrm{g}_{\mathrm{gly}}^{-1}$, which equals $0.51 \pm 0.06 \mathrm{~mol}_{\mathrm{mal}} \mathrm{mol}_{\mathrm{gly}}^{-1}$ ). Interestingly, the rate in the culture with $250 \mathrm{~g} \mathrm{~L}^{-1}$ glycerol as starting concentration is only $22 \%$ lower than the rate achieved with $150 \mathrm{~g} \mathrm{~L}^{-1}$ glycerol, even though the overall $\mathrm{OD}_{600}$ of the former culture is less than half of the latter. It seems that with high glycerol concentrations, the specific production rate per gram biomass is higher, although quantification is difficult due to possible differences in intracellular lipid formation, which significantly influences the biomass composition of Ustilago under these conditions [30, 35].

\section{Separation of growth and production}

Ustilaginaceae and other fungi generally only initiate organic acid production upon depletion of an essential nutrient $[35,36]$, which poses an inherent trade-off between biomass and product formation. In order to investigate this trade-off, as well as to establish the minimal set of compounds needed during the malic acid production phase, cells grown for $24 \mathrm{~h}$ in $50 \mathrm{~mL}$ MTM containing $0.8 \mathrm{~g} \mathrm{~L}^{-1} \mathrm{NH}_{4} \mathrm{Cl}$ and $50 \mathrm{~g} \mathrm{~L}^{-1}$ glycerol were centrifuged, washed twice with demineralized water, and transferred to $50 \mathrm{~mL}$ of an aqueous solution of 100 or $200 \mathrm{~g} \mathrm{~L}^{-1}$ glycerol. The resting cell conversion was either buffered with $100 \mathrm{~g} \mathrm{~L}^{-1} \mathrm{CaCO}_{3}$ (200 $\mathrm{g} \mathrm{L}^{-1}$ glycerol), $100 \mathrm{mM}$ MES (Fig. 4), or not buffered at all $\left(100 \mathrm{~g} \mathrm{~L}^{-1}\right.$ glycerol) (data not shown).

In the $\mathrm{CaCO}_{3}$-buffered conversion, a concentration of $129 \pm 11 \mathrm{~g} \mathrm{~L}^{-1}$ malic acid was reached after $384 \mathrm{~h}$ corresponding to a production rate of $0.34 \pm 0.03 \mathrm{~g} \mathrm{~L}^{-1} \mathrm{~h}^{-1}$ (Fig. 4a), which equals the production rate of normal cultivations with $200 \mathrm{~g} \mathrm{~L}^{-1}$ initial glycerol (compare Fig. 2). In the MES-buffered system, the resulting titer was significantly lower, reaching $4.01 \pm 0.08 \mathrm{~g} \mathrm{~L}^{-1}$ (Fig. 4c), while the unbuffered control produced only $20 \pm 1 \mathrm{mg} \mathrm{L}^{-1}$. Both in the MES-buffered and in the unbuffered system, the $\mathrm{pH}$ dropped below 5.5 and 4.5,
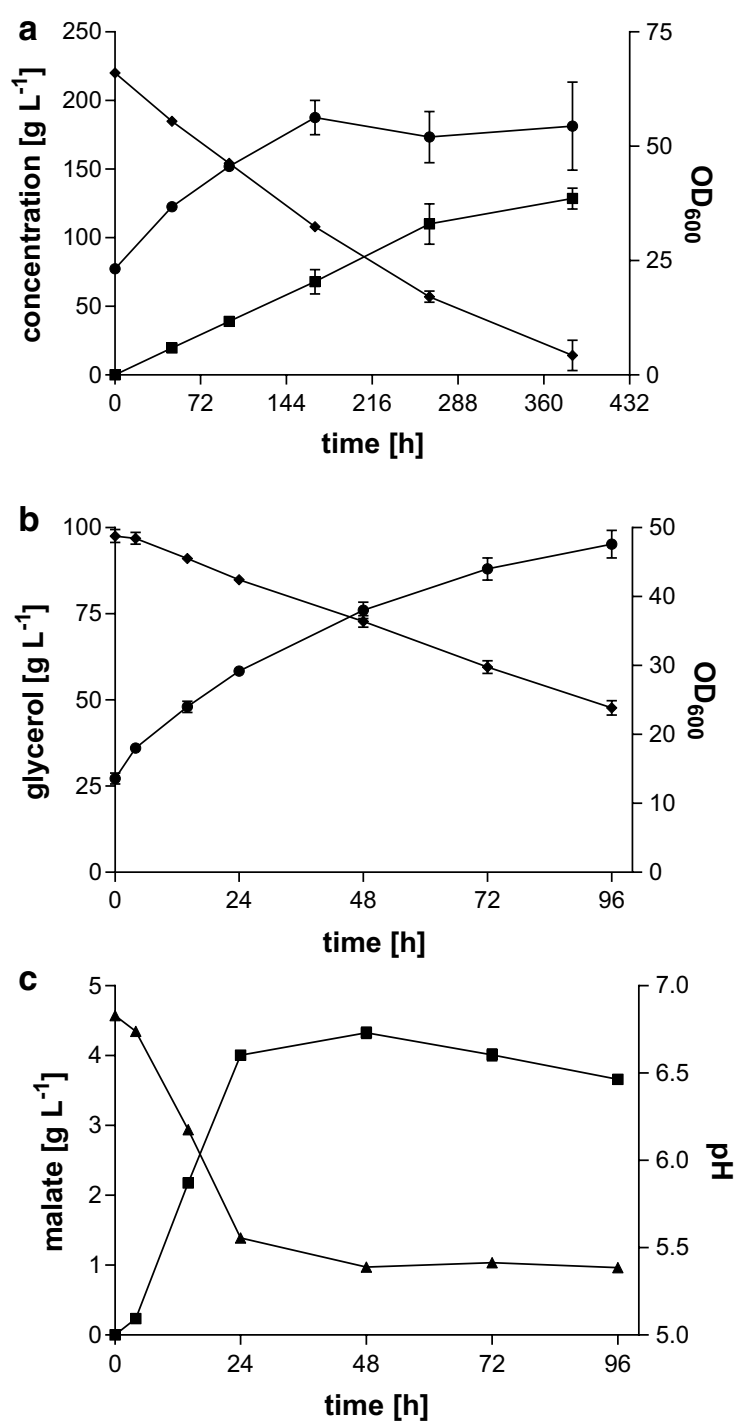

Fig. 4 Malic acid production of U. trichophora TZ1 cells in shake flasks with aqueous glycerol solutions. Cultures contained either $200 \mathrm{~g} \mathrm{~L}^{-1}$ glycerol buffered with $100 \mathrm{~g} \mathrm{~L}^{-1} \mathrm{CaCO}_{3}(\mathbf{a})$, or $100 \mathrm{~g} \mathrm{~L}^{-1}$ glycerol buffered with $100 \mathrm{mM}$ MES buffer $(\mathbf{b}, \mathbf{c}) . \mathrm{OD}_{600}$ (circles), malic acid concentration (squares), glycerol concentration (diamonds), and pHvalue (triangles). Error bars indicate deviation from the mean $(n=2)$

respectively, in contrast to the $\mathrm{CaCO}_{3}$-buffered system, which stayed above $\mathrm{pH} 6.0$ throughout the production. These data indicate that during the production phase, no supplements in the medium are needed. The $\mathrm{pH}$, however, is a critical parameter. In 2014, Geiser et al. [13] were already able to show the significant influence of buffer capacity on acid production with Ustilaginaceae. They cultivated Ustilaginaceae in differing concentrations of MES-buffer. Comparable to our data, a drop in $\mathrm{pH}$ inhibited further acid production. Apparently, a $\mathrm{pH}$ 
greater than 5.4 is needed for efficient malate production with $U$. trichophora TZ1. Interestingly, even without further malate production in the MES-buffered system the glycerol consumption rate stays constant for $72 \mathrm{~h}$. This suggests the activity of an overflow metabolism, possibly switching to alternative products, such as extracellular glycolipids, polyols, or $\mathrm{CO}_{2}$. Additionally, with both buffers, $\mathrm{OD}_{600}$ increases more than 2.5-fold, even though no source of nitrogen, phosphate, or trace elements was present. This increase in $\mathrm{OD}_{600}$ can for a large part be attributed to the production of intracellular lipids [30]. A significant increase in dry cell weight after nitrogen limitation has also already been reported by Klement et al. [35] in 2012. They could show that the cell number still increased by about $30 \%$ after limitation. However, the carbon-to-nitrogen weight ratio in the biomass increased from 5.9 in cells during unlimited growth to about 20 in cells during stationary phase, clearly showing that the increasing $\mathrm{OD}_{600}$ is a result of nitrogen "dilution." Consequently, one additional division cycle is possible after nitrogen depletion, which probably does not positively affect the bio-catalytic potential, since the total amount of proteins remains the same [35]. In addition, a significant amount of glycerol is used for lipid formation, which mainly occurs after nitrogen depletion. Although this generally detracts from the overall efficiency of malate production, the lipids themselves are a useful secondary product for food, cosmetic, or biofuel applications, and their inclusion in the cells makes them relatively easy to separate. These phenomena may partly explain the yield of $0.43 \pm 0.00 \mathrm{~mol}_{\text {mal }} \mathrm{mol}_{\text {gly }}^{-1}$, which is lower than the yield in cultures with complete mineral media containing $200 \mathrm{~g} \mathrm{~L}^{-1}$ glycerol $(0.49 \pm 0.00)$ even though no glycerol is needed for biomass production. In addition, the lack of micronutrients likely serves as an additional stress factor which reduces the cells' productivity and tolerance to malate.

In all, these results indicate the high potential of $U$. trichophora TZ1 as production organism for malic acid. Although the overall production rate of $0.50 \pm 0.08 \mathrm{~g} \mathrm{~L}^{-1} \mathrm{~h}^{-1}$ is lower than reported rates for other organisms [11], a titer of almost $200 \mathrm{~g} \mathrm{~L}^{-1}$ is reached with a strain that is not genetically modified. To our knowledge, this titer is the highest reported value for microbial malic acid production. In the future, this process can be taken to bioreactors for further improvement, making full use of $U$. trichophora's unicellular growth, focusing on increasing the production rate and final titer while circumventing handling and downstream processing issues associated with $\mathrm{CaCO}_{3}$ cultures. These issues include problems of oxygenation by shaking due to high viscosity and the general drawback of a huge gypsum waste stream for industrial scale processes resulting from production processes involving $\mathrm{CaCO}_{3}$ as buffering or downstream processing agent.

By this, the overall production process for malic acid with $U$. trichophora could be further improved, making $U$. trichophora a promising industrially applicable production organism for malic acid.

\section{Conclusions}

The microbial conversion of glycerol to value-added chemicals has been the focus of research for many years. The identification and optimization of $U$. trichophora TZ1 as efficient malate producer opens up novel opportunities for glycerol valorization, potentially adding to the overall feasibility of a biodiesel bio-refinery. The reached titer of almost $200 \mathrm{~g} \mathrm{~L}^{-1}$ is the highest titer reported for any microbial malic acid production, and further improvements in the production rate and yield can be expected from process optimization and metabolic engineering. Especially, the generation of a closed carbonbalance would shed light on possible targets, since it would clarify the amount of glycerol used for by-product formation and respiration. Abovementioned facts reveal the potential for further research and improvement of $U$. trichophora TZ1 as promising, industrially applicable production organism for malic acid, or as a gene donor of interest for heterologous malate producers. This confirms in general the potential of the Ustilaginaceae for bio-catalysis.

\section{Methods}

\section{Strains and culture conditions}

The 68 strains belonging to the family Ustilaginaceae screened by Geiser et al. [13] in 2014, except for Ustilago avenae CBS 131466 (2216), plus Ustilago maydis DSM 3121 (1949), U. maydis DSM 4500 (1950), U. maydis DSM 14603 (1951), U. maydis Nr. 483 ATCC 22902 (21702), U. maydis Nr. 495 ATCC 22914 (2179), U. trichophora CBS 131473 (2219), and Ustilago hordei Uh4875-4 Mat1 [37] were screened in this study. The numbers in parenthesis indicate in-house strain numbers.

As standard medium, MTM was used according to Geiser et al. [13] with $0.2 \mathrm{~g} \mathrm{~L}^{-1} \mathrm{MgSO}_{4} 7 \mathrm{H}_{2} \mathrm{O}$, $10 \mathrm{mg} \mathrm{L}^{-1} \mathrm{FeSO}_{4} 7 \mathrm{H}_{2} \mathrm{O}, 0.5 \mathrm{~g} \mathrm{~L}^{-1} \mathrm{KH}_{2} \mathrm{PO}_{4}, 1 \mathrm{~mL} \mathrm{~L}^{-1}$ vitamin solution, $1 \mathrm{~mL} \mathrm{~L}^{-1}$ trace element solution, and $0.8 \mathrm{~g} \mathrm{~L}^{-1} \mathrm{NH}_{4} \mathrm{Cl}$ and $50 \mathrm{~g} \mathrm{~L}^{-1}$ glycerol, unless stated otherwise. As buffer, either $100 \mathrm{mM}$ MES or differing concentrations of $\mathrm{CaCO}_{3}$ were used. When using solid $\mathrm{CaCO}_{3}$ buffer, the concentration of medium components is always based on the total volume of liquid and solid.

For solid medium screening, plates with MTM containing $20 \mathrm{mM} \mathrm{MES} \mathrm{pH} \mathrm{6.5,} 2$ \% (w/v) Agar-Agar, and 
$0.02 \mathrm{~g} \mathrm{~L}^{-1}$ methyl red were used. $10 \mu \mathrm{L}$ of an overnight culture, grown in MTM with $10 \mathrm{~g} \mathrm{~L}^{-1}$ glucose and $100 \mathrm{mM}$ MES was spotted on the plates in duplicates and the plates were incubated at $30^{\circ} \mathrm{C}$ for 9 days.

For adaptive laboratory evolution, $U$. trichophora was grown in MTM with $100 \mathrm{mM}$ MES in 100-mL Erlenmeyer flasks with $10 \%(\mathrm{v} / \mathrm{v})$ filling volume. $\mathrm{OD}_{600}$ was measured daily until an $\mathrm{OD}_{600}$ of $>16$ was reached, after which a new culture was inoculated to an $\mathrm{OD}_{600}$ of 0.5 . This procedure was repeated sequentially for 57 days. Growth rates of evolved and original strains were assessed in separate cultures in MTM with $\mathrm{CaCO}_{3}$ as buffer.

Medium optimization was performed in 24-deep well plates (Enzyscreen, System Duetz ${ }^{\circledR}$ ) with $1.5 \mathrm{~mL}$ MTM containing either MES or $\mathrm{CaCO}_{3}$ and differing concentrations of $\mathrm{FeSO}_{4}$ and $\mathrm{KH}_{2} \mathrm{PO}_{4}$ incubated at $30{ }^{\circ} \mathrm{C}$ (relative air humidity $=80 \%$ ) shaking at $300 \mathrm{rpm}$ (shaking diameter $=50 \mathrm{~mm}$ ).

Shake flask production experiments were conducted in 500-mL Erlenmeyer flasks with $10 \%(\mathrm{v} / \mathrm{v})$ filling volume. All cultures were incubated at $30{ }^{\circ} \mathrm{C}$ (relative air humidity $=80 \%$ ) shaking at $200 \mathrm{rpm}$ (shaking diameter $=25 \mathrm{~mm}$ ). As preculture, MTM with $100 \mathrm{mM} \mathrm{MES}$ was inoculated from an overnight YEP culture and grown over night. All shake flask cultures were inoculated to a starting $\mathrm{OD}_{600}$ of 0.5 . All yields were calculated based on the actual amount of glycerol consumed.

\section{Analytical methods}

All experiments were performed in duplicates. Shown is the arithmetic mean of the duplicates. Error bars and \pm values indicate deviation from the mean.

When using $\mathrm{CaCO}_{3}$ as buffer, $1 \mathrm{~mL}$ of culture broth was taken for $\mathrm{OD}_{600}$ determination and HPLC analysis. The $\mathrm{CaCO}_{3}$ was dissolved with $\mathrm{HCl}$ prior to further measurements. $\mathrm{OD}_{600}$ was determined in an Ultrospec 10 cell density meter (Amersham Biosciences, UK), samples were diluted to an $\mathrm{OD}_{600}$ between 0.1 and 0.8 .

For HPLC analysis, centrifuged samples (13.000 g, $5 \mathrm{~min}$ ) were filtered through cellulose acetate filters (diameter $0.2 \mu \mathrm{m}$, VWR, Germany) and subsequently diluted 1:10 with distilled water. Glycerol and organic acids were analyzed on a Dionex Ultimate 3000 HPLC (Dionex, USA) with an Organic Acid Resin column (CSChromatographie, Germany) kept at $75{ }^{\circ} \mathrm{C}$, with a constant flow rate of $0.8 \mathrm{~mL} \mathrm{~min}^{-1}$ of $5 \mathrm{mM}$ sulfuric acid as eluent. For detection, a Shodex RI 101 detector at $35{ }^{\circ} \mathrm{C}$ and a variable wavelength UV detector (Dionex, USA) at $210 \mathrm{~nm}$ were used.

Ammonium concentration was determined by a colorimetric assay according to Willis [38].

\section{Abbreviations}

MTM: modified Tabuchi medium; ALE: adaptive laboratory evolution; MES: 2-(N-morpholino) ethanesulfonic acid; HPLC: high-performance liquid chromatography.

\section{Authors' contributions}

$L M B$, NW, and GM conceived and designed the project. TZ, NW, JMB, and LMB designed experiments and analyzed results. TZ and NW wrote the manuscript with the help of LMB and JMB. TZ performed the screening and adaptive laboratory evolution experiments. ES, WK, and TZ performed shake flask experiments. All authors read and approved the final manuscript.

\section{Author details}

${ }^{1}$ Institute of Applied Microbiology-iAMB, Aachen Biology and Biotechnology-ABBt, RWTH Aachen University, Worringerweg 1, 52074 Aachen, Germany. 2 BRAIN AG, 64673 Zwingenberg, Germany.

\section{Acknowledgements}

We thank Elena Geiser for technical assistance and valuable discussion.

\section{Competing interests}

GM and JMB are paid employees of BRAIN AG. The authors declare that no financial or non-financial competing interest was present with regard to the results or interpretation of the reported experiments. Further, they declare that this does not alter the permission of unrestricted use, distribution, and reproduction in any medium, provided the original author and source are credited.

\section{Funding}

This study was partially funded by Biotechnology Research and Information Network AG (BRAIN AG) and by the German Federal Ministry of Education and Research (BMBF) as part of the Strategic Alliance ZeroCarbFP (Grant No. FKZ 031A217F).

Received: 1 February 2016 Accepted: 10 March 2016

Published online: 17 March 2016

\section{References}

1. Battat E, Peleg Y, Bercovitz A, Rokem JS, Goldberg I. Optimization of L-malic acid production by Aspergillus flavus in a stirred fermentor. Biotechnol Bioeng. 1991;37(11):1108-16.

2. Sauer M, Porro D, Mattanovich D, Branduardi P. Microbial production of organic acids: expanding the markets. Trends Biotechnol. 2008;26(2):100-8.

3. Werpy T, Petersen GR, Aden A, Bozell JJ, Holladay J, White J, Manheim A, Eliot D, Lasure L, Jones S. Top value added chemicals from biomass. Volume 1 -results of screening for potential candidates from sugars and synthesis gas; 2004.

4. Goldberg I, Rokem JS, Pines O. Organic acids: old metabolites, new themes. J Chem Technol Biotechnol. 2006;81(10):1601-11.

5. Abe S, Furuya A. Method of producing I-malic acid by fermentation. 1962.

6. Magnuson JK, Lasure LL. Organic acid production by filamentous fungi. In: Tkacz JS, Lange L, editors. Advances in fungal biotechnology for industry, agriculture and medicine. New York; 2004. p. 307-340.

7. Zelle RM, de Hulster E, van Winden WA, de Waard P, Dijkema C, Winkler AA, Geertman JM, van Dijken JP, Pronk JT, van Maris AJ. Malic acid production by Saccharomyces cerevisiae: engineering of pyruvate carboxylation, oxaloacetate reduction, and malate export. Appl Environ Microbiol. 2008;74(9):2766-77.

8. West TP. Malic acid production from thin stillage by Aspergillus species. Biotechnol Lett. 2011;33(12):2463-7.

9. Moon SY, Hong SH, Kim TY, Lee SY. Metabolic engineering of Escherichia coli for the production of malic acid. Biochem Eng J. 2008;40(2):312-20.

10. Zhang $X$, Wang $X$, Shanmugam KT, Ingram LO. L-malate production by metabolically engineered Escherichia coli. Appl Environ Microbiol. 2011;77(2):427-34.

11. Brown SH, Bashkirova L, Berka R, ChandlerT, Doty T, McCall K, McCulloch M, McFarland S, Thompson S, Yaver D, et al. Metabolic engineering of 
Aspergillus oryzae NRRL 3488 for increased production of L-malic acid. Appl Microbiol Biotechnol. 2013;97(20):8903-12.

12. Klement T, Büchs J. Itaconic acid-a biotechnological process in change. Bioresour Technol. 2013;135:422-31.

13. Geiser E, Wiebach V, Wierckx N, Blank LM. Prospecting the biodiversity of the fungal family Ustilaginaceae for the production of value-added chemicals. BMC Fungal Biol Biotechnol. 2014;1:2.

14. Yang F, Hanna MA, Sun R. Value-added uses for crude glycerol-a byproduct of biodiesel production. Biotechnol Biofuels. 2012;5:13.

15. Anand P, Saxena RK. A comparative study of solvent-assisted pretreatment of biodiesel derived crude glycerol on growth and 1, 3-propanediol production from Citrobacter freundii. N Biotechnol. 2012;29(2):199-205.

16. Bozell JJ, Petersen GR. Technology development for the production of biobased products from biorefinery carbohydrates-the U.S. Department of Energy's "Top 10" revisited. Green Chem. 2010;12(4):539-54

17. West TP. Crude glycerol: a feedstock for organic acid production by microbial bioconversion. J Microbial Biochem Technol. 2012; 4

18. MuY, Teng H, Zhang DJ, Wang W, Xiu ZL. Microbial production of 1, 3-propanediol by Klebsiella pneumoniae using crude glycerol from biodiesel preparations. Biotechnol Lett. 2006;28(21):1755-9.

19. Otte B, Grunwaldt E, Mahmoud O, Jennewein S. Genome shuffling in Clostridium diolis DSM 15410 for improved 1, 3-propanediol production. Appl Environ Microbiol. 2009;75(24):7610-6.

20. Ashby RD, Solaiman DKY, Foglia TA. Bacterial poly(hydroxyalkanoate) polymer production from the biodiesel co-product stream. J Polym Environ. 2004;12(3):105-12.

21. Saenge C, Cheirsilp B, Suksaroge TT, Bourtoom T. Potential use of oleaginous red yeast Rhodotorula glutinis for the bioconversion of crude glycerol from biodiesel plant to lipids and carotenoids. Process Biochem. 2011;46(1):210-8.

22. Scholten E, Renz T, Thomas J. Continuous cultivation approach for fermentative succinic acid production from crude glycerol by Basfia succiniciproducens DD1. Biotechnol Lett. 2009:31(12):1947-51.

23. Papanikolaou S, Muniglia L, Chevalot I, Aggelis G, Marc I. Accumulation of a cocoa-butter-like lipid by Yarrowia lipolytica cultivated on agro-industrial residues. Curr Microbiol. 2003;46(2):124-30.

24. RymowiczW, Rywinska A, Marcinkiewicz M. High-yield production of erythritol from raw glycerol in fed-batch cultures of Yarrowia lipolytica. Biotechnol Lett. 2009;31(3):377-80.

25. Dragosits M, Mattanovich D. Adaptive laboratory evolution_-principles and applications for biotechnology. Microb Cell Fact. 2013;12:64.
26. Sauer U. Evolutionary engineering of industrially important microbial phenotypes. Adv Biochem Eng Biotechnol. 2001;73:129-69.

27. Sonderegger M, Sauer U. Evolutionary engineering of Saccharomyces cerevisiae for anaerobic growth on xylose. Appl Environ Microbiol. 2003;69(4):1990-8.

28. Kuyper M, Toirkens MJ, Diderich JA, Winkler AA, van Dijken JP, Pronk JT. Evolutionary engineering of mixed-sugar utilization by a xylose-fermenting Saccharomyces cerevisiae strain. FEMS Yeast Res. 2005;5(10):925-34.

29. Ibarra RU, Edwards JS, Palsson BO. Escherichia coli K-12 undergoes adaptive evolution to achieve in silico predicted optimal growth. Nature. 2002;420(6912):186-9.

30. Maassen N, Panakova M, Wierckx N, Geiser E, Zimmermann M, Bölker M, Klinner U, Blank LM. Influence of carbon and nitrogen concentration on itaconic acid production by the smut fungus Ustilago maydis. Eng Life Sci. 2013;14(2):129-34.

31. Batti M, Schweiger L. Process for the production of itaconic acid. 1963.

32. Jeon JM, Rajesh T, Song E, Lee HW, Lee HW, Yang YH. Media optimization of Corynebacterium glutamicum for succinate production under oxygendeprived condition. J Microbiol Biotechnol. 2013;23(2):211-7.

33. Zelle RM, de Hulster E, Kloezen W, Pronk JT, van Maris AJA. Key process conditions for production of $\mathrm{C} 4$ dicarboxylic acids in bioreactor batch cultures of an engineered Saccharomyces cerevisiae strain. Appl Environ Microbiol. 2010;76(3):744-50.

34. Michielsen MJF, Frielink C, Wijffels RH, Tramper J, Beeftink HH. Growth of Ca-D-malate crystals in a bioreactor. Biotechnol Bioeng. 2000;69(5):548-58.

35. Klement T, Milker S, Jäger G, Grande PM, de Maria PD, Büchs J. Biomass pretreatment affects Ustilago maydis in producing itaconic acid. Microb Cell Fact. 2012;11:43.

36. Kubicek CP, Punt P, Visser J. Production of organic acids by filamentous fungi. In: Hofrichter M, editors. Industrial Applications. 2011. 215-234.

37. Linning R, Lin D, Lee N, Abdennadher M, Gaudet D, Thomas P, Mills D, Kronstad JW, Bakkeren G. Marker-based cloning of the region containing the UhAvr1 avirulence gene from the basidiomycete barley pathogen Ustilago hordei. Genetics. 2004;166(1):99-111.

38. Willis RB, Montgomery ME, Allen PR. Improved method for manual, colorimetry determination of total Kjeldahl nitrogen using salicylate. J Agric Food Chem. 1996;44(7):1804-7.

\section{Submit your next manuscript to BioMed Central and we will help you at every step:}

- We accept pre-submission inquiries

- Our selector tool helps you to find the most relevant journal

- We provide round the clock customer support

- Convenient online submission

- Thorough peer review

- Inclusion in PubMed and all major indexing services

- Maximum visibility for your research

Submit your manuscript at www.biomedcentral.com/submit 